\title{
DEVELOPMENT AND VALIDATION OF REVERSED PHASE HPLC METHOD FOR ESTIMATION OF SIMVASTATIN IN PHARMACEUTICAL DOSAGE FORM
}

\author{
${ }^{*} J_{a t}$ R.K ${ }^{1}$, Sharma $S^{2}$, Chhi pa RC ${ }^{1}$, Singh Rambir ${ }^{1}$, Alam Imran ${ }^{1}$, \\ ${ }^{1}$ Department of Pharmacy, Suresh Gy an Vihar University, Rajasthan, India-302025 \\ ${ }^{2}$ Department of Pharmaceutical Science, Guru Jambheshwar University, Hisar, Hariy ana-125001 \\ *Corresponding Auththor's E-mail: rakeshiat75@yahoo.co.in
}

Received 24 March 2012; Revised 20 April 2012; Accepted 24 April 2012, Available online 15 May 2012

\begin{abstract}
ABS TRACT
A simple, accurate rapid and precise RP-HPLC method has been developed and validated for determination of simvastatin in bulk drug. The RP-HPLC separation was achieved on Promosil C-18, $(250 \mathrm{~mm}, 4.6 \mathrm{~mm}, 5 \mu \mathrm{m}) \mathrm{using}$ mobile phase buffer: methanol ph $6.8(96: 4 \mathrm{v} / \mathrm{v})$ at flow rate of $1.0 \mathrm{ml} / \mathrm{min}$ at ambient temperature. The retention times were $9.546 \mathrm{~min}$. for simvastatin. Calibration plots were linear over the concentration range $1-50 \mu \mathrm{g} / \mathrm{ml}$. Quantification was achieved with photodiode array detection at $254 \mathrm{~nm}$ over the concentration range of $1-50 \mu \mathrm{g} / \mathrm{ml}$. The method was validated statistically and applied successfully for the determination of simvastatin. Validation studies revealed that method is specific, rapid, reliable, and reproducible. The high recovery and low relative standard deviation confirm the suitability of the method for the routine determination of simvastatin in bulk drug.

Key words: Simv astatin, Water, Buffer, Validation, HPLC.
\end{abstract}

\section{INTRODUCTION}

Simvastatin is 2, 2 -dimethyl butanoic acid (1S, 3R, 7S, 8S, 8aR) - 1, 2, 3, 7, 8, 8a-he xahydro-3, 7-d imethyl-8-[2[(2R,4R) tetrahydro -4- hydroxy l- 6 -о xo-2H pyran-2yl]ethyl-1-naphthalenyl ester ${ }^{12}$ belongs to the group of cholesterol-lowering lactones known as statins which, in 2007, were identified as being the most widely prescribed drugs in the world. Statins lower cholesterol by inhibiting the synthesis of mevalonic acid, which is a key precusor in cholesterol synthesis. SMT, a lipid lowering agent that is derived synthetically from a fermentation product of Aspergillus terreus has been found to lessen both normal and elevated LDL-C concentrations.<smiles>O=C1C[C@@H](O)CCO1</smiles>

Figure 1: Chemical structure of Simvastatin

The drug is officially listed in 2004 United States Pharmacopocia and the official method of its determination is UV-spectrophotometry ${ }^{3-5}$, and various other methods are HPTLC $^{6}$, miscellar eletrokinetic chromatography and voltammetry ${ }^{7}$ have been reported for the assay of SMT in pharmaceuticals. The method development bottleneck result from the requirement to generate a quantitative and qualitative profile of impurities, enabling the reporting of the identity of each chemical moiety ${ }^{8}$. Two official methods utilising HPLC GRADIENT methodology are reported in European Pharmacopoeia (EP) and United State Pharmacopoeia (USP) ${ }^{9,10}$.

\section{MATERIALS AND METHODS}

All the reagents used were of HPLC grade and analytical grade and were purchased from Merck Chemicals, India. Reference standard of Simvastatin was supplied as gift sample from Sun Pharmaceutical Laboratories Limited, Mumbai with purity of $99.987 \%$.

\section{- Preparation of buffer solution:}

Mix $5 \mathrm{~mL}$ of glacial acid in $1000 \mathrm{~mL}$ of milli Q water. To $1000 \mathrm{~mL}$ of $5 \mathrm{~mL}$ glacial acetic acid solution, add $0.94 \mathrm{gm}$ of 1-Hexane sulphonic acid anhydrous sonicate to dissolve.

- Preparation of Mobile phase: The mobile phase is prepared by mixing buffer: methanol in the ratio of 96:4 Filtered and degas it

- Chromatographic Run:

Load the standard solution of simvastatin in the injector, enter the HPLC parameters as per (Table: 1 ), save the method, inject and run for $20 \mathrm{~min}$.

- Standard preparation of simvastatin Accurately weigh and transfer about $20 \mathrm{mg}$ of drug simvastatin working standard into $100 \mathrm{~mL}$ volu metric flask, and about $70 \mathrm{~mL}$ of diluents, sonicate to dissolve, dilute to volume with diluents and mix. Filter the solution through $0.45 \mu \mathrm{m}$.

- Prepar ation of system suitability solution ${ }^{8}$. Accurately weigh and transfer about 10mg of working standard into $100 \mathrm{ml}$ volu metric flask. Add $25 \mathrm{~mL}$ of $0.1 \mathrm{~N} \mathrm{HCl}$ and $25 \mathrm{~mL}$ of Diluent. Sonicate to dissolve. Keep the sample at about $80{ }^{\circ} \mathrm{C}$. For 4 hours. Use this solution as system suitability solution.

- Preparation of placebo solution ${ }^{8}$

Accurately weigh and transfer powdered content of placebo equivalent to $100 \mathrm{mg}$ of Drug into $100 \mathrm{~mL}$ volumetric flask. Add about $70 \mathrm{~mL}$ diluent and sonicate for about $15 \mathrm{~min}$. dilute to the volume and mix. Filter the solution through $0.45 \mu \mathrm{m}$ filters. 
Preparation of diluents: Use mobile phase as diluents

As in Figure-2
Mobile phase $=$ Methanol: Buffer pH 4.0 (96:4)

Mobile phase $=$ Methanol: Buffer pH 4.0 (96:4)

Table 1: Chromatographic conditions for the optimized method for Simvastatin

\begin{tabular}{|l|l|l|}
\hline S. No. & \multicolumn{1}{|c|}{ Parameters } & \multicolumn{1}{c|}{ Description } \\
\hline 1. & Instrument & A HPLC instrument (Younglin series) with Model Acme-9000 \\
\hline 2. & Column & Promosil C-18, $(250 \mathrm{~mm}, 4.6 \mathrm{~mm}, 5 \mu \mathrm{m})$ \\
\hline 3. & Mobile Phase & $\begin{array}{l}\text { Mix } 5 \mathrm{ml} \text { of glacial acid in 1000ml of water. To 1000ml of 5ml glacial acetic acid solution, add } \\
0.94 g m \text { of 1-Hexane sulphonic acid anhy drous. Sonicate to dissolve. The mobile phase is prepared by } \\
\text { mixing buffer: methanol in the ratio of 96:4 Filtered and degas it. }\end{array}$ \\
\hline 4. & & $1.0 \mathrm{~mL} / \mathrm{minute}$ \\
\hline 5. & Flow Rate & $254 \mathrm{~nm}$ \\
\hline 6. & Injection Volume & $10 \mu \mathrm{L}$ \\
\hline 7. & Run Time & $20 \mathrm{Minutes}$ \\
\hline
\end{tabular}

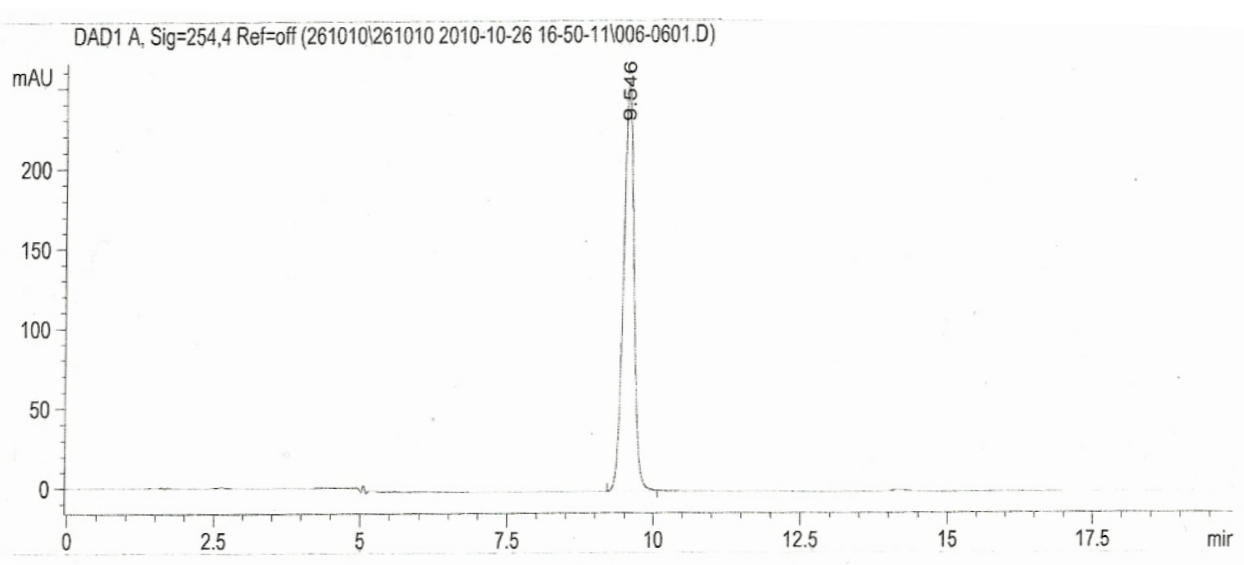

Figure 2: Representive chromatograms of standard solution of Simvastatin

\section{METHOD VALIDATION}

The developed method was validated according to ICH guidelines. Standard calibration curve were prepared in the mobile phase with 5 concentration ranging from 1-50 $\mu \mathrm{g} / \mathrm{ml}$ for simvastatin is injected in to HPLC system keeping the injection volume constant. The peak area was plotted against the corresponding concentration to obtain the calibration graphs. To study the reliability and suitability of developed method, recovery experiments were carried out at three levels 80, 100 and $120 \%$. Known concentration of Commercial tablet is spiked with known amounts of simvastatin. At each level of the amount six determinations were performed and the results obtained were compared with expected results. Recovery for pharmaceutical formulations should be within the range $100 \pm 5 \%$. The percent R.S.D of individual measurements was also determined. Precision of the assay was determined by repeatability (intra-day) and intermediate precision (inter-day) for 3 consecutive days. Three different concentration of simvastatin were analysed in six independent series in the same day (intra-day precision) and 3 consecutive days (inter-day precision). The repeatability of sample application and measurement of peak area for active compounds were expressed in terms of percent RSD.

All chromatograms were examined to determine if compounds of interest co-eluted with each other or with any additional excipient peaks. Marketed formulation were analysed to determine the specificity of the optimized method in the presence of common tablet excipients. Limi of detection (LOD) and limit of quantitation (LOQ) were estimated from single to noise ratio. LOD and LOQ were calculated using 3.3\%/s and $10 \sigma / \mathrm{s}$ formulae, respectively. Where $\sigma$ the standard deviation of the peak areas and $s$ is is the slope of the corresponding calibration curve. To evaluate robustness of HPLC method a few parameters included variation of flow rate, percentage of buffer in the mobile phase, and $\mathrm{pH}$ of mobile phase.

\section{RES ULT AND DISCUSSION}

The retention time of simvastatin was peak eluted at 9.546 min. The peaks are well separated with a resolution of 3.344 and Tailing 1.136 .

The mobile phase comprises of Methanol: Buffer (96:4) $\mathrm{v} / \mathrm{v}$ at the $\mathrm{pH} 4.0$ was selected as optimized mobile phase, because of the high purity, symmetry, proper tailing, high area and low RT value at same concentration as compared to other trail mobile phase. Furthermore, the stability of the drug in the mobile phase were also studied and result indicating that the drug Simvastatin was found to be stable during the storage time of $48 \mathrm{hr}$ (Table 2).

Linearity of the method was investigated by serially diluting the working standard to give a concentration range of $1-10 \mu \mathrm{m} / \mathrm{ml}$ and $20 \mu \mathrm{l}$ from this was injected. The flow rate was maintained at $1 \mathrm{ml} / \mathrm{min}$. temperature of colu $\mathrm{mn}$ was kept ambient and the effluent was monitored at 254 nm. Calibration curve was constructed by plotting concentration against peak area (fig.3). 
Table 2: Stability of the simvastatin in the optimized mobile phase

\begin{tabular}{|l|l|l|l|l|l|}
\hline S. N. & Storage condi tions & Mean area \pm SD $($ At zero hrs $)$ & SE & Mean area \pm SD $($ At 48 hrs $)$ & SE \\
\hline 1. & $\begin{array}{l}\text { Roo } \mathrm{m} \text { Temperature } \\
\left(25 \pm 0.5^{0} \mathrm{C}\right)\end{array}$ & $252952.3 \pm 2859.82$ & 3474.9 & $248844.7 \pm 3650.63$ & 2777.53 \\
\hline 2. & Refrigerator $\left(4 \pm 0.5^{0} \mathrm{C}\right)$ & $252952.3 \pm 2859.82$ & 3474.9 & $250011.3 \pm 3653.10$ & 2778.63 \\
\hline
\end{tabular}

*Concentration of drug $10 \mu \mathrm{g} / \mathrm{ml}$ in mobile phase.

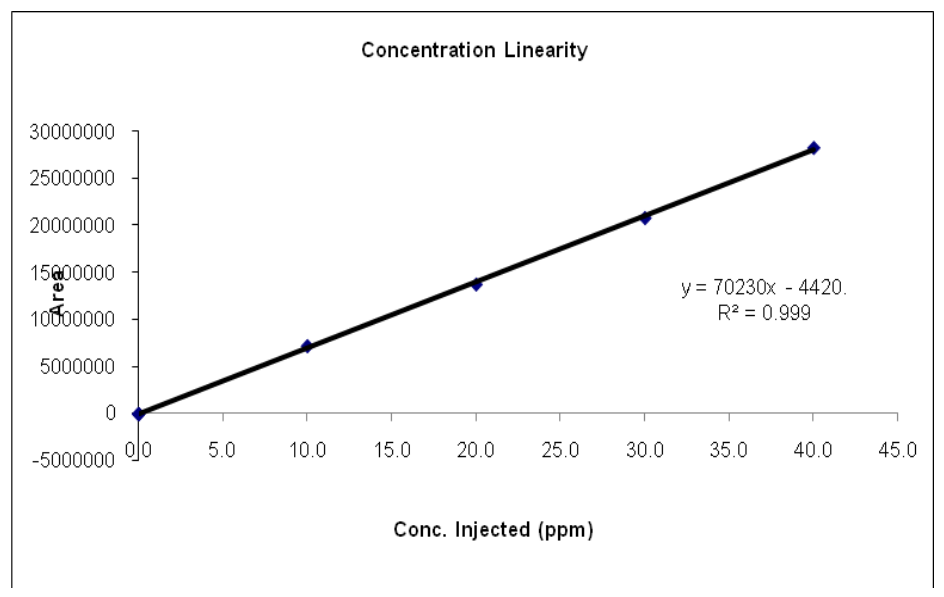

Figure 3: Standard Curve of Simvastatin

The method was validated for linearity, precision, accuracy, specificity, limit of detection and limit of quantification as per ICH guidelines. All parameters are validated as per ICH guide lines.

Optimum condition of mobile phases was investigated in the development of an HPLC method suitable for analysis of in the bulk drug. These included Methanol: Acetonitrile: Buffer (50:20:30) (\% v/v), Methanol: Acetonitrile: Buffer (60:20:20), Methanol: buffer (50:50), Methanol: Buffer
(70:40), Methanol: Buffer pH 4.0 (90:10), and Methanol: Buffer pH 4.0 (96:4).The same solvent mixture was used for extraction of the drug from the formulation containing excipients. The retention time of Simvastatin obtained was $9.546 \pm .234$ (1). The system suitability tests for HPLC were carried out on freshly prepared solution of Simvastatin $(10 \mu \mathrm{g} / \mathrm{ml})$ and parameters were studied. The results were summarized in Table 3.

Table 3: System sutability test for Simvastatin:

\begin{tabular}{|c|c|c|}
\hline S. No. & Parameter & Value \\
\hline 1. & Retention time, min & $9.546 \pm 0.234$ \\
\hline 2. & Tailing factor & $1.136 \pm 0.274$ \\
\hline 3. & Asymmetry factor & $1.139 \pm 0.864$ \\
\hline 4. & Theoretical plates & $5642 \pm 0.426$ \\
\hline 5. & Resolution & $3.344 \pm 0.628$ \\
\hline
\end{tabular}

Assay of tablets of Simvastatin were perfomed. Twenty tablets of each company of strength $5 \mathrm{mg}, 10 \mathrm{mg}$ and 20 mg were weighed and ground to a fine powder. A quantity of tablet powder equivalent to $10 \mathrm{mg}$ of Simvastatin was transferred to $10 \mathrm{ml}$ volu metric flask, dissolved and diluted with acetonitrile and water mixture to obtain $1 \mathrm{mg} / \mathrm{ml}$. The solution was sonicated for 15 minute and filtered through
$0.45 \mu \mathrm{m}$ membrane filter. The solution was further diluted to obtain concentration $10 \mu \mathrm{m} / \mathrm{ml}$. Peak area of the above prepared tablet solutions of Simvastatin were measured by using above mentioned chromatographic conditions and the amount of Simvastatin were found from regression equation (Table 4) \& Recovery study (Table 5).

Table 4: Results of Analysis of Commercial Tablets of Simvastatin

\begin{tabular}{|l|c|l|l|l|}
\hline $\begin{array}{l}\text { Tablet } \\
\text { Formulation }\end{array}$ & Label claim(mg) & $\begin{array}{l}\text { \% Label claim estimated* (Mean } \pm \\
\text { S.D.) }\end{array}$ & \% Coeff. Of Variation & Standard error \\
\hline I(SIM) & 5 & $99.435 \pm 1.243$ & 1.365 & 0.514 \\
\hline II(SIMCARD) & 10 & $99.754 \pm 1.509$ & 1.523 & 0.625 \\
\hline III (SIMCHOL) & 20 & $99.246 \pm 1.427$ & 1.305 & 0.613 \\
\hline
\end{tabular}

*Ave rage of six determinations

Table 5: Recovery Studies of Commercial Tablets of Simvastatin

\begin{tabular}{|l|c|c|c|c|c|}
\hline $\begin{array}{l}\text { Tablet } \\
\text { Formulation }\end{array}$ & $\begin{array}{c}\text { Label claim } \\
(\mathbf{m g})\end{array}$ & $\begin{array}{c}\text { Drug added } \\
(\mathbf{m g})\end{array}$ & $\begin{array}{c}\text { \% Label claim } \\
\text { estimated* (Mean } \pm \text { S.D.) }\end{array}$ & $\begin{array}{c}\text { \% Coeff. of } \\
\text { Variation }\end{array}$ & Standard error \\
\hline I(SIM) & 5 & 2.5 & $99.316 \pm 1.513$ & 1.496 & 0.743 \\
\hline II(SIMCARD) & 10 & 5 & $99.514 \pm 1.397$ & 1.432 & 0.574 \\
\hline III (SIMCHOL) & 20 & 10 & $99.288 \pm 0.863$ & 0.798 & 0.465 \\
\hline
\end{tabular}

*Ave rage of six determinations 
The linear regression date showed a good linear relationship over the concentration range of $1-50 \mu \mathrm{g} / \mathrm{ml}$ as summarized in Table 6. The limit of detection (LOD) and the limit of quantification(LOQ) of the drug were found by scanning the solution of Simvastatin having different lower concentrations and the LOD and LOQ were found to be 0.5 and $1 \mu \mathrm{g} / \mathrm{ml}$ indicates that method is sensitive (Table 6 ). The intraday and interday precision were determined by analyzing standard solution of Simvastatin at three different concentration levels $(6,8,10 \mu \mathrm{g} / \mathrm{ml})$. The $\%$ RSD for intraday and interday precision was found to be 0.257 $0.712 \%$ and $0.480-1.080 \%$ respectively which indicate that method is precise (Table 6).

Table-6: Stastiscal Data \& Regression Equation for Simvastatin

\begin{tabular}{|l|l|l|}
\hline $\mathrm{S}$. & & \\
$\mathrm{N}$. & Parameter & Value \\
\hline 1. & $\lambda_{\max }(\mathrm{nm})$ & 254 \\
\hline 2. & Beer's range $\mu \mathrm{g} / \mathrm{ml})$ & $5-40$ \\
\hline 3. & Molar absorbtivity $(\mathrm{l} / \mathrm{mol} / \mathrm{cm})$ & $4.327 \times 10^{4}$ \\
\hline 4. & Correlation coefficient $\left(\mathrm{r}^{2}\right)$ & 0.999 \\
\hline 5. & Regression equation & $\mathrm{Y}=0.70230 \mathrm{X}-4420$ \\
\hline 6. & Intercept $(\mathrm{a})$ & 04420 \\
\hline 7. & Slope $(\mathrm{b})$ & 0.70230 \\
\hline 8. & Limit of detection $(\mathrm{LOD} \mu \mathrm{g} / \mathrm{ml})$ & 0.126 \\
\hline 9. & Limit of quantification $(\mathrm{LOQ} \mu \mathrm{g} / \mathrm{ml})$ & 0.406 \\
\hline 10. & Linearity & $1-50$ \\
\hline 11. & Accuracy $\%$ & 99.16 to 101.24 \\
\hline 12. & Repeatability $(\mathrm{RSD}, \%, \mathrm{n}=6)$ & 0.195 \\
\hline 13. & Precision $(\mathrm{RSD}, \%)$, Interday $(\mathrm{n}=6)$ & $0.480-1.080 \%$ \\
\hline 14. & Intraday $(\mathrm{n}=6)$ & $0.257-0.712 \%$ \\
\hline
\end{tabular}

Repeatability of the method was studied by injecting 10 $\mu \mathrm{g} / \mathrm{ml}$ solution of Simvastatin for six times and peak area was measured and \% RSD was calculated which was found to be 0.195 shows repeatability of the method (Table

\section{REFERENCES}

1. Merck index, Maryadele J.O.Neil Edu. In: 13th ed. Published by Merck Research Lab., NJ, USA. 2001, 868.

2. Bays HE, Moore PB, Drehobl MA et al: Effectiveness and tolerability of simvastatin in patients with primary hypercholesterolemia: pooled analy sis of two phase II studies. Clin Ther 2001, 23 (8), 1209-1230.

3. Marczenko Z, Separation and spectrophotometric determination of elements, Mary Masson, Edition, ELLIS HORWOOD Limited Publishers, 2001, 216, 222, 240, 319, 435, 631.

4. Wang L, Asgharnejad L, J.Pharm.Boimed.Anal. 2000, 21, 1243.

5. Arayne MS, Sultana N, Hussain F, Ali SA, J. Anal. Chem. 2007, 26, 536.

6. Vickers S, Duncan CA, Chen IW, Rosemary A, Duggan DE, Drug Metab. Dispos. 1990, 18, 138-145.

7. United States Pharmacopoeia, USP30-NF25, Pharmacopeial Forum. 2002, 32(1), 3179.
6). Accuracy of the method was evaluated by standard addition method in which appropriate portion of stock solutions of Simvastatin were spiked into blank placebo matrix to produce concentrations of 80100 and $120 \%$ of theoretical concentration. The mean recovery of spiked samples obtained was in range of 99.16 to 101.24 reveals no interference of excipients and shows that method is accurate (Table 6).

The proposed validated method was successfully applied to determine Simvastatin in tablet form. The results obtained for tablets of Simvastatin were comparable with the corresponding labeled amounts $(0.5 \mathrm{mg} / \mathrm{tab})$ (table 4$)$. Robustness of the method was estimated by changing the mobile phase composition $(3 \pm 3)$, wavelength $\pm 1 \mathrm{~nm}$, injection volume $(20 \pm 2 \mu 1)$, column temperature $\left(40 \pm 3^{0}\right)$ and RSD values for all these changes calculated were less than 2 indicate that proposed method is robust. The proposed RP-HPLC method was accurate, precise, sensitive and rapid. The method also can be extended for the routine analysis of Simvastatin in tablet dosage form.

\section{CONCLUSION}

It is thus concluded that the proposed method is new, simple, cost effective, accurate, safe, free from pollution and precise and can be successfully employed in the routine analysis of these drugs in pharmaceutical dosage forms. The proposed method shall prove equally effective to analyze Simvastatin in the corresponding drug sample and may prove to be of great importance in pharmaceutical analysis.

\section{ACKNOWLEDGEMENT}

Authors are grateful to Suresh Kalwania (Senior Chemist) and M/s. Sun Pharma Lab, Jammu for providing the gift samples of drugs.

8. Jat R.K., Chhipa R.C. and Sharma S., spectrophotometric quantification of Carviedilol inbulk drug and tablets,.Pharmacophore ,2010, 1(2), 90-95.

9. Jat R.K., Chhipa R.C. and Sharma S., spectrophotometric quantification of Etiricoxib inbulk drug and tablets using hy drotropic agents.Pharmacophore ,2010, 1(2), 96-102.

10. Martindale the comlete drug reference, published by high street lodon, Edition 36, 2009, 1390-96.

11. Europian Pharmacopoeia. Council of Europe, Strasburg Cedex. 2002, $4^{\text {th }}$ Edition,

12. Jat R.K., Chhipa R.C. and Sharma S., quantitative estimation of clobazam inbulk drug and tablet.IJCPRR, 2011, 1(3), 1824.

13. Jat R.K., Chhipa R.C. and Sharma S., Spectrophotometric Estimation of Fluvoxamine Maleate in Tablets Using Hydrotropic Agent, IJPQR,2011,2(4); 73-75 